\title{
42- Kültürlerarası yaklaşım bağlamında Almancanın yabancı dil olarak öğretilmesinde film kullanımı
}

Ferdiye ÇOBANOĞULLARI'

APA: Çobanoğulları, F. (2021). Kültürlerarası yaklaşım bağlamında Almancanın yabancı dil olarak öğretilmesinde film kullanımı. RumeliDE Dil ve Edebiyat Araştırmaları Dergisi, (25), 726-736. DOI: $10.29000 /$ rumelide.1032522.

\section{$\ddot{O} \mathbf{z}$}

Dil ve kültür arasındaki sıkı ilişki, yabancı dil öğretimini etkilemiştir. Günümüzde, yabancı dil öğretiminde artık hedef ülkenin kültürünün de öğretilmesine önem verilmektedir. Özellikle, seksenli yılların ortasından itibaren etkili olmaya başlayan kültürlerarası yaklaşım, yabancı dil öğretiminin merkezine kültür öğretimini ve ülke bilgisini koymaktadır. Ancak okullarda yabancı dil öğretiminde temel öğretim materyali olarak kullanılan kitaplar, bazen kültür öğretimi için yeterli olmamaktadır. Kitaplara ek olarak, kültür öğretiminde kullanılabilecek en önemli materyaller arasında filmler bulunmaktadır. Filmler hem görsel hem işitsel materyaller oldukları için yabancı dil öğretimi ve kültür öğretiminde birçok avantaja sahiptir. Betimsel yöntemin kullanıldığı bu çalışmada, filmlerin Almanca derslerinde kültür öğretimine ne gibi katkılar sağlayacağını tespit etmek amacıyla, Alman yapımı "Kückückskind” adlı film "Kültürlerarası Yaklaşım” bağlamında incelenmiştir. Film, Türk ve Alman aile hayatını konu edindiği için bünyesinde birçok kültürel unsur bulundurmaktadır. Öncelikle filmlerin yabancı dil derslerinde nasıl kullanılabileceği açıklanmış ve sonrasında ise seçilmiş bazı sahnelerdeki kültürel içerikler değerlendirilmiştir. Ayrıca filmlerle kültür öğretiminde, ne gibi alıştırmaların yapılması gerektiği örnekler ile birlikte açıklanmıştır. Yapılan inceleme sonucunda "Kückückskind” adlı filmin Türk ve Alman kültürü hakkında ön yargıları yansıttı̆̆ı ve iki kültür arasında karşılaştırma imkânı sağladığı görülmüştür. Ayrıca bu film öğrencilere, Almanya'da yaşayan Türkler ile Türkiye'de yaşayan Türkleri karşılaştırma imkânı da sağlamaktadır. Sonuç olarak film, sahip olduğu bu kültürel içeriklerle Almanca derslerinde kültür öğretimine katkı sağlayacaktır.

Anahtar kelimeler: Yabancı dil öğretimi, kültürlerarası yaklaşım, kültür, film, Almanca

\section{The use of film in teaching German as a foreign language in the context of intercultural approach}

\begin{abstract}
The close relationship between language and culture has influenced the foreign language teaching. Nowadays, the culture of the target country is considered important in foreign language teaching. Especially, the intercultural approach which has been effective since the middle of the eighties, places the teaching of culture and information about the target country at the center of foreign language teaching. However, the course books that are used as basic teaching material in foreign language teaching in schools are sometimes not sufficient for culture teaching. In addition to course books, movies are among the most important materials that can be used in culture teaching. As the movies are both visual and auditory materials, they have many advantages in foreign language and culture teaching. In this study which was used descriptive method, it was analyzed the German movie named
\end{abstract}

Öğr. Gör. Dr., Gazi Üniversitesi, Yabancı Diller Yüksekokulu, Almanca Bölümü (Ankara, Türkiye), ferdiyec@gazi.edu.tr, ORCID ID: 0000-0003-4025-7858 [Araştırma makalesi, Makale kayıt tarihi: 20.09.2021-kabul tarihi: 20.10.2021; DOI: 10.2900o/rumelide.1032522] 


\begin{abstract}
"Kückückskind" in the context of the "Intercultural Approach" with the aim of determining how the movies would contribute to culture teaching in German lessons. Due to the fact that the movie focuses on Turkish and German family life, it includes many cultural elements in it. Primarily, it was explained how movies should be used in foreign language lessons, and then cultural contents in selected scenes were evaluated. It is also explained with examples, which exercises should be used in culture teaching with movies. As a result of the analyses, it was observed that the movie named "Kückückskind" reflected the preconceptions about the Turkish and German culture and provided a comparison between the two cultures. Additionally, this movie provides also the opportunity to compare the Turkish people who live in Turkey and Germany. Consequently, the movie will contribute to culture teaching in German lessons with these cultural contents.
\end{abstract}

Keywords: Foreign language teaching, intercultural approach, culture, movie, German

\title{
1. Giriş
}

Uzun yıllardır yabancı dil öğretimi ile ilgili alanlarda yapılan çalışmalarda, sürekli olarak kültürün önemi vurgulanmaktadır. Dilbilimciler ve dil alanında çalışmalar yapan araştırmacılar, dilin kültürün bir parçası olduğu ve kültürden ayrı düşünülemeyeceği konusunda hemfikirdir. Aksan'a göre (2009a: 15) bir insan doğduğu zaman, anadilinin dilbilgisi kurallarını, söz varlı̆̆ını ve kavramlarını çevresinde hazır bulmakta ve anadiliyle düşünüp, dünyayı onunla algılamaktadır. Bu açıklamaya dayanarak farklı dillere mensup kimselerin dünyayı algılayış biçimlerinin de birbirinden farklı olduğunu söylenebilir. Dili şekillendiren ve insanların dünyayı farklı şekillerde algılamasını să̆layan en büyük etkenlerden biri de dilin içinde bulunduğu kültürdür. Göktürk (2016: 15) her dilin, belli bir kültürün göstergeler dizgesiyle, belli uzlaşımlarıyla, davranışlarıyla, töre ve değer yargılarıyla, genel anlamda somut insan yaşamıyla iç içe olduğunu belirtmektedir.

Dil ve kültür arasındaki bu sıkı bağ, yabancı dil öğretimde de kültürün ön plana çımasına sebebiyet vermiştir ve bu doğrultuda yabancı dil öğretilirken kültürün de öğretilmesi için yeni yöntem ve yaklaşımlar ortaya atılmıştır. Bunlardan biri de seksenli yılların ortasından itibaren etkili olmaya başlayan "Kültürlerarası Yaklaşım" dır. Genel anlamda, dil öğretiminde kültürün önemini vurgulayan bu yaklaşımla son ylllarda kitapların içerikleri kültür öğretimini destekleyen alıştırmalar, okuma parçaları ve benzeri etkinliklerle yeniden şekillendirilmiştir.

Ancak İşcan'ın (2017: 437) da belirttiği gibi yazılı materyaller hedef dilin kültürü hakkında daha sınırlı oranda bilgiler sunmaktadır ve bu sebeple başka materyallere de ihtiyaç duyulmaktadır. Filmler, gerçek hayattan kesitler sunan hem görsel hem de işitsel açıdan zengin materyallerdir. Bundan dolayı, kültür öğretiminde yazılı materyallere ek olarak kullanılabilecek en uygun materyaller arasındadır. Ayrıca sınıf içerisinde çeşitli materyallerin kullanması öğrencilere daha zengin ve zevkli bir öğretim ortamının sunulmasına katkı sağlayacaktır. Betimsel yöntemin kullanıldı̆̆ı bu çalışmada ise Türk ve Alman aile yapılarını yansıtan "Kückkückskind" adlı Alman yapımı film, kültürlerarası yaklaşım bağlamında birçok açıdan incelenip Almanca derslerinde kullanılması durumunda kültür öğretimine ne gibi katkılar sağlayabileceği saptanmaya çalışllacaktır.

\section{Almanca öğretiminde kültürlerarası yaklaşım}

Kültür ve dil arasındaki ilişki ve sorunların incelenmesi 18. yüzyıldan itibaren önem kazanmaya başlamıştır. Özellikle Herder, Wilhelm von Humboldt ve Whorf gibi önemli düşünürler dil kültür 

736)

ilişkisini vurgulamaktadırlar (Aksan, 2009b: 64). Yabancı dil öğretimi alanında ise dil-kültür ilişkisi, iletişimsel yöntemin bir devamı olarak ortaya atılan ve seksenli yılların ortasından itibaren etkisini göstermeye başlayan "Kültürlerarası Yaklaşım” ile önem kazanmıştır. Bu yaklaşıma göre yabancı dili doğru şekilde kullanılmak tek başına yeterli değildir, hedef kültürü anlamak da önemlidir. Bu yaklaşım kapsamındaki öğretimlerde ülke bilgisi ve evrensel temalar ön plana çımaktadır. Kültür odaklı yabancı dil öğretimi sadece hedef kültürün anlaşılmasını sağlamamakta, ayrıca kişinin kendi kültürünün de bilincinde olmasını sağlamaktadır. Bu yaklaşımla yabancı dil öğrenen bireye, erek kültürden biri ile karşı karşıya geldiğinde empati kurabilme yetisi ve kültürel çeşitlilikler karşısında toleranslı davranabilme yetisi kazandırılmaya çalışılmaktadır. Bu yaklaşımın temel hedefleri arasında bireyleri kültürlerarası temaslara hazırlamak, yaşanabilecek kültür şoklarını, yanlış anlaşılmaları ve ön yargıları engellemek bulunmaktadır. Bu yaklaşım çerçevesinde işlenen derslerde bireyin kendi kültürü ile hedef kültürü karşılaştırabilmesi, konu üzerine konuşabilmesi ve yabancı dilde kendini ifade edebilmesi önemlidir (Kalkan, 2014: 141-143). Bu yaklaşım ile Almanca derslerinde öğrencilerden, Alman kültürünü tanıması, kendi kültürü ile Alman kültürü arasında karşılaştırma yapabilmesi, Alman kültürüne karşı toleranslı davranması ve bir Alman ile empati kurması beklenmektedir.

Avrupa'da ve Türkiye'de yabancı dil öğretiminde kullanılmakta olan "Diller için Avrupa Ortak Başvuru Metni” değerlendirme ve referans sisteminde de kültürlerarası yaklaşımın prensiplerine rastlanmaktadır. Bu metinde kültürlerarası bilinç üzerinde durulmaktadır. Kültürlerarası bilinçle anlatılmak istenen, bireyin kendi kültürü ile hedef kültür arasındaki yöresel ve sosyal farklılıkların farkında olmasıdır. Metne göre yabancı kültüre ait bilgiler dil öğrenen bireyin önceki deneyim alanında kalmış olabilir ve basmakalıp düşüncelerle zedelenmiş olabilir. Bu yüzden yabancı dil öğrenen birey sosyokültürel bilgilere önem vermelidir. Sosyokültürel bilginin içeriğini de günlük yaşam, yaşam koşulları, kişilerarası ilişkiler, inançlar ve tutumlar, beden dili, sosyal gelenekler ve geleneksel davranışlar (kutlamalar, doğum, evlenme, ölüm kutlamalar vb.) oluşturmaktadır. Yabancı dil öğrenen bir birey kültürlerarası beceri de kazanmalıdır (Avrupa Konseyi, 2013: 103-105). Bu becerinin içeriği ise metinde (s.105-106) aşağıdaki şekilde belirtilmektedir:

- Kişinin kendi kültürü ile yabancı kültürü ilişkilendirme yeteneği

- Başka kültürden kişilerle iletişim kurmak için gerekli stratejileri tanıma ve kullanabilme yeteneği

- Kendi kültürü ile yabancı kültür arasında köprü kurabilme, kültürlerarası anlaşmazlık ve çatışma söz konusu olduğunda bunlarla baş edebilme

- Kalıplaşmış ilişkileri aşma yeteneği

- Almanca derslerinin içeriğini şekillendiren bu çerçeve doğrultusunda, öğrencilerden Alman kültürü hakkında bilinç ve sosyokültürel bilgilere sahip olmaları beklenmektedir. Alpar'a (2013, s. 104) göre kültürel kavramlar anlaşılırsa, farklı kültürlerden insanların dünyayı nasıl gördüğünü ve başkalarına vermiş oldukları tepkileri daha kolay fark edilebilir. Bunun tersi olduğunda ise verilen tepkilerin sebebi anlaşılmayabilir ve kişi kendince bu tepkilere anlamlar yükleyebilir. Yücel (2009: 34-36) Alman kültürü hakkında yeterli bilgiye sahip olmayan bir Türk’ün Almanca konuşabilse bile yaşayabileceği sorunlara örneklerle açlklık getirmiştir. Bu örnekler aşağıda verilmiştir: 
- Ahmet, Almanya'da dil kursiyeridir. Eve giderken arkadaşıyla kafeye gitmekte olan komşusu Michael ile karşlaşır. Michael Ahmet’i de kahve içmeye davet eder. Almanca pratik yapmak için firsat yakalayan Ahmet, teklifi kabul eder. Kafede keyifli vakit geçirdikten sonra Michael hesabı ayrı ödemek ister. Ahmet bu hareket karşısında şaşırır. Ahmet ülkesinde döndükten sonra Almanların misafirperver ve cömert olmadıkları düşüncesine kapılır.

Bu örnekte, Ahmet'in Almanlar hakkında olumsuz düşüncelere kapılmasının sebebi Michael'in hesabı ayrı ödemek istemesinden kaynaklanmaktadır. Bilindiği üzere, Türk kültüründe genellikle davet eden kişi hesabı ödemektedir. Ancak Alman kültüründe bu yaygın bir davranış değildir. Bu durum karşısında Almanlar hakkında kötü düşüncelere kapılmak yerine, onların kültüründe böyle bir davranışın olmadığının bilincinde olup, olayı normal karşılamak sağlıklı ilişkilerin sürdürülmesi için gereklidir.

Ayrıca eğitim sürecinde üzerinde durulması gereken en önemli noktalardan biri de insan onuruna ve haklarının eşitliğine saygı duyulmasının gerekliliğidir (Cinkara, 2016: 115). Bu bağlamda kültürlerarası yaklaşım eğitim sürecine büyük katkı sağlayacaktır.

\section{Almanca derslerinde filmlerle kültür öğretimi}

Yabancı dil derslerinde film kullanımı, çok yönlü eğitim sürecine katkıda bulunmaktadır (Malaguti \& Thoma, 2012: 3). Filmler sadece dil öğretiminde değil, ayrıca kültür öğretiminde de kullanılan önemli materyallerdir. Filmlerde birçok kültürel unsur yer almaktadır. Örneğin dilin farklı ă̆ızları, şiveleri, yazı şekilleri, gelenek ve görenekler, tabular ve buna benzer daha birçok kültürel unsur filmlerde gösterilmekte ve öğretmene öğretim sürecinde yardımcı olmaktadır. En önemlisi de filmler gerçek yaşamı, popüler kültürü, sanatı, kültürel ve estetik imgeleri gerçekçi şekilde yansıtmaktadır (İşcan, 2017: 442, 444).

Aime Toth (2010, s. 49) filmlerin dil öğretiminde kültürlerarası perspektifi genişleten zengin firsatlar sunduğunu ve insanların, filmlerde ekonomik bir zaman dilimi içerisinde farklı ve karmaşı iletişimsel durumlarda gösterildiğini belirtmiştir. Ona göre bu durum, öğrencinin hedef dil ve ülkenin birçok yönünü fark etmesine olanak sağlamaktadır. Leitzke Ungerer (2009: 15) ise filmlerle kültürlerarası öğrenmenin, filmdeki kurgusal dünyayı eleştirel bir şekilde inceleme, ayrıca kültürel benzerlik ve farklılıkları yansıtabilme becerisini içerdiğini ifade etmektedir.

Filmin, kültür öğretimine katkısı olabilmesi için seçilen filmin bazı özelliklerine dikkat edilmelidir. Derste kullanılmak üzere seçilmiş filmde ve kullanımında dikkat edilmesi gereken bazı hususlar şöyle özetlenebilir (Tognozzi, 2010):

- Gösterilecek her sahnenin 1 buçuk 2 dakikadan fazla olmamasına dikkat edilmelidir.

- Seçilen sahnelerde tercihen diyalog olmalıdır ve diyalogların en fazla iki kişi arasında geçtiği sahneler kullanılmalıdır.

- Öğrenciler öncesinde ne olduğunun bilmeden, seçilen sahnedeki diyaloğu anlayabilmelidir.

- Sahneler gerçek hayattan kesitler barındırmalı, günlük konuşmalara yer vermelidir.

- Sahnede yer alan kişilerin yüz, el vb. hareketleri izleyicinin tepkilerine uygun olmalıdır. 
Bunların dışında filmin konusuna, filmin içeriğine, filmdeki dilin öğrencilerin dil seviyesine uygun olup olmadığına da dikkat edilmelidir. Cinsellik ve şiddet içeren sahneler gösterilmemeli, amaç kültür öğretmek ise kültürel unsurlar barından filmler seçilmelidir. En önemlisi de tüm ders boyunca sadece film izletilmemelidir. Film öncesi, film esnası ve sonrası için çeşitli etkinlikler hazırlanmalıdır (İşcan, 2017: 445-446). Ying ve Hai-Feng (2012: 1012-1013) filmlerle yabancı dil öğretimi için bir takım film öncesi, esnası ve sonrası uygulanmak üzere bazı aktiviteler önermiştir. Bu öneriler aşağıdaki gibi özetlenebilir:

\section{- Film Öncesi Uygulanabilecek Aktiviteler}

Film izletilmeden önce, sınıfa filmin afişi vb. materyaller getirilebilir. Filmin konusu, kültürel arka planı hakkında öğrencilere bilgi verilebilir. Bunun yanında filmdeki karakterler ve karakterlerin birbiriyle olan bağları hakkında bilgi verilebilir. Filmin adından yola çıkılarak, filmin ne hakkında olabileceği üzerinde kısa tartışmalar yapılabilir. Film öncesi gerekli bilgilerin verilmesi izletilen sahnelerin daha kolay anlaşılmasını sağlayacaktır.

- Film Esnasinda Uygulanabilecek Aktiviteler

Belli başlı sahneler izletilirken öğretmenin önceden hazırladığı boşluk doldurma, çoktan seçmeli ve doğru- yanlış testleri kullanılabilir. Alman kültürünün öğretilmesi hedefleniyorsa filmdeki kültürel bilgilere yönelik testler hazırlanmalıdır.

- Film Sonrası Uygulanabilecek Aktiviteler

Filmin bazı sahneleri izletildikten sonra öğrencilerin, izlediklerinden ne gibi anlamlar çıkardıklarını ölçmek, izlediklerini pekiştirmek için onlara grup tartışması, rol oynama yaptırılabilir, film hakkında kompozisyon veya özet yazdırılabilir.

Ders saatinin kısıtlı olduğu düşünülürse, filmin kültür öğretimine en çok fayda sağlayacak sahneleri seçilip gösterilmeli ve aktivitelere de yeterli zaman ayrılmalıdır.

\section{Kückückskind filminin kültür öğretimi bağlamında incelenmesi}

“Kückkückskind” adlı film 2014 yllında Almanya'nın Köln şehrinde çekilmiştir. Film, doğumda hastanede çocukları karışan Türk ve Alman ailenin, 16 yıl sonra bu gerçeği öğrenmesi ve birbirlerinin hayatını daha yakından tanımak için ailelerin çocuklarını iki haftalığına takas etmesini konu edinmektedir (Internet Movie Database/ IMDb, 2017). Türk ve Alman oyuncu kadrosundan oluşan film, Türk ve Alman aile yaşamını konu edinmesiyle bünyesinde birçok kültürel unsur bulundurmakta ve iki kültürü karşılaştırma imkânı sağlamaktadır. Bu sebeple kültür öğretimi için çeşitli açılardan incelenmek istenmiştir. Film altyazısız olarak kullanılacaksa, başlangıç seviyesindeki öğrenciler için zor olabilir. Bu yüzden daha ileri seviyedeki öğrenciler veya üniversitede Almanca bölümlerinde okuyan öğrenciler için kullanılması daha uygun olacaktır.

Film izletilmeden önce film ile alakalı genel bilgiler, sahnelerin daha iyi anlaşılabilmesi için öğrencilere verilmelidir. Örneğin aşağıdaki gibi bir tablo hazırlanabilir: 
Tablo 1: Kückückskind filmindeki karakterler hakkında genel bilgiler

\begin{tabular}{ll}
\hline Alman Aile & Türk Aile \\
\hline Anne: Antonia Greve (Moda & Anne: Hatice Güngör (Ev Hanımı) \\
Tasarımcısı & Baba: Erdal Güngör (Pazarcı) \\
Baba: Claus Greve (Mimar) & Çocuklar: Fatma Güngör (en büyük), Ayşe Güngör (Dominik ile karışan \\
Çocuk: Dominik Greve & çocuk) \\
Ailenin Durumu: Boşanmış & Dilek Güngör (en küçük) \\
& Ailenin Durumu: Evli \\
\hline
\end{tabular}

Filmin yılı, nerede çekildiği, konusu ile bilgiler sözlü olarak verilebilir. Filmin afişi sınıfa getirilerek öğrencilerin filmin konusu hakkında tahminlerde bulunması istenebilir. Bunların dışında filmden bir sahnenin resmi gösterilebilir ve üzerine tartışma yapılabilir.

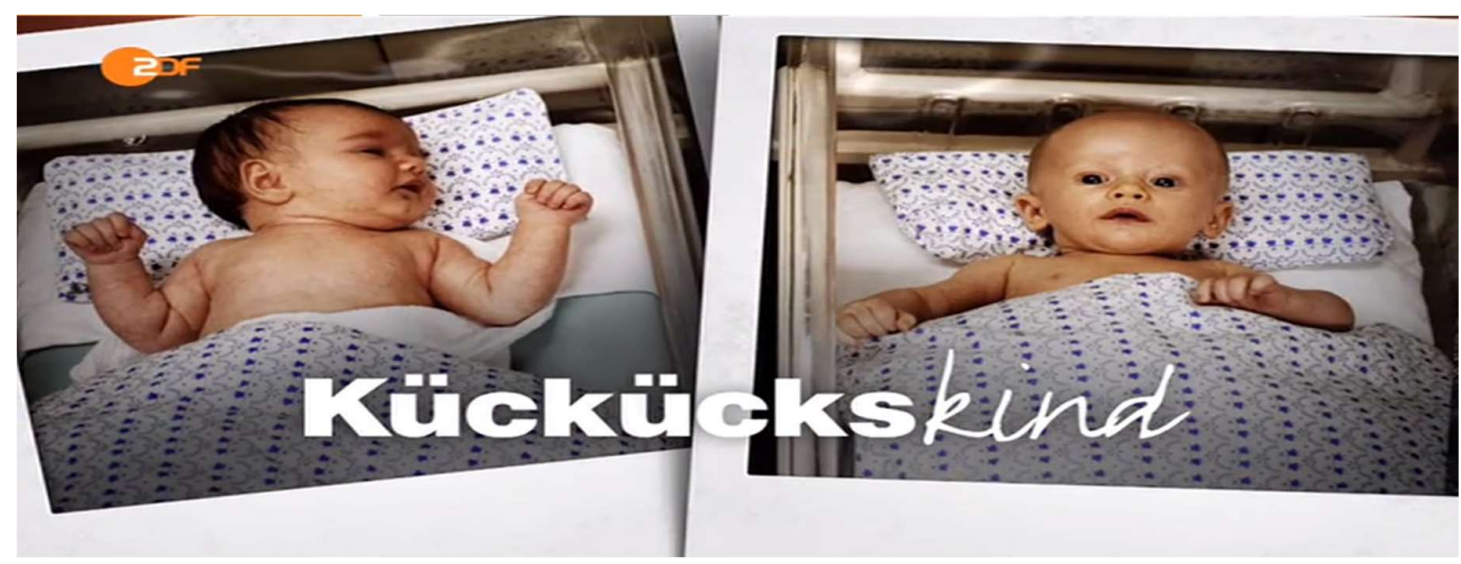

Resim 1: Kückückskind filminin afişi ( https://www.listal.com/viewimage/9867475 )

Film kesitlerinin izletilmesinden önce film afişi üzerinde tartışmak, en faydalı ön hazırlık aşamalarından biri olduğu söylenebilir. Öğrencilere film afişi ile ilgili sorular yöneltilerek, film hakkında değerlendirmelerde bulunmaları istenebilir.

Örn.: Filmin afişi, filmin konusu hakkında ne gibi ip uçları vermektedir?

Örn.: Afişteki bebekler kim olabilir? İkisi arasındaki bağlantı nedir?

Örn.: Afişteki mekan neresidir?

Örn.: Filmin adı neden “Kückückskind” olarak seçilmiştir? 
The use of film in teaching German as a foreign language in the context of intercultural approach / F. Çobanoğulları (pp. 726736)

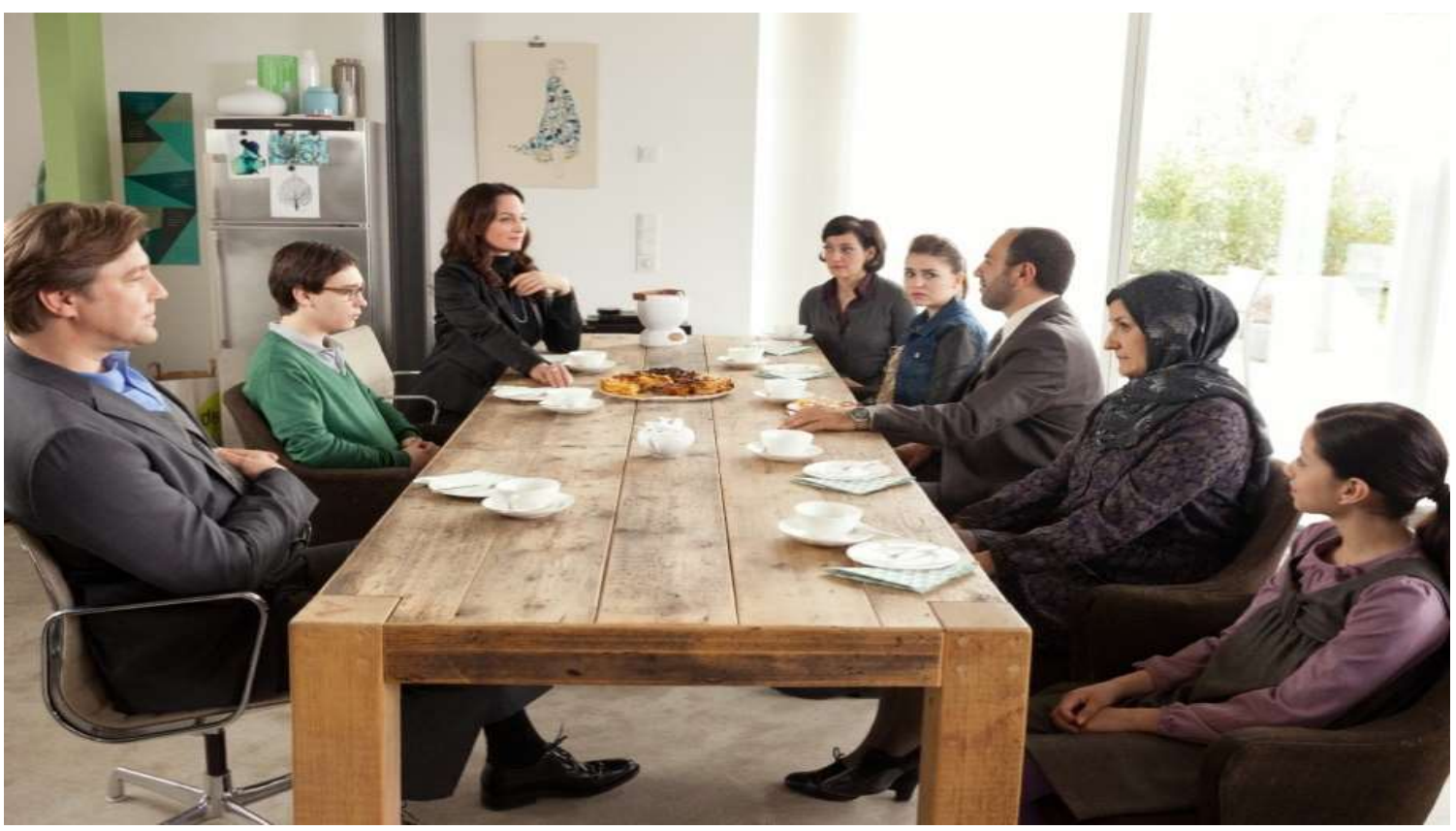

Resim 2: Kückückskind filminde yer alan Türk ve Alman aile (ZDF-Thomas Kost/kino.de)

Filmdeki sahneler gösterilmeden bile, filmden bazı sahnelerin fotoğrafları birtakım kültürel içeriğin aktarılmasına yardımcı olabilir. Örneğin Resim2, karakterlerin kılık kıyafetleri, aile yapıları hakkında bilgiler vermektedir. Türk ailenin Alman aileye göre daha kalabalık olduğu geleneksel aile yapısı taşıdığı görülmektedir.

Film hakkında yeterli ön bilgi edinildikten sonra seçilmiş sahneler gösterilmelidir. Kültürel unsurlar taşıyan bazı sahneler şöyledir:

- o0:06:16 - oo:06.35 aralığındaki sahnede kızının dışarıda kısa şort giydiğini gören Türk baba kızına "-Kızım bu ne? Utanmıyor musun? Ah kızım Ah." diye tepki vermektedir. Kız (Ayşe) ise korkuyla babasından kaçmaya çalışmakta ve yanında taşıdığı uzun eteği üzerine geçirmeye çalışmaktadır.

- 00:25:56 - 00.27:03 aralığındaki sahnede Türk ailenin evinde çocukların doğumda hastanede karıştığı açıklanmaktadır. Bu sahne birçok kültürel içerik barındırmaktadır. Öncelikle Türklerin mütevazı bir evde yaşadığı görülmekte ve duvarlarda dini motifli tablolar göze çarpmaktadır. Bunun dışında Türkler bozuk bir Almanca konuşmakta ve Almanca konuşurken araya Türkçe kelimeler katmaktadır. En dikkat çeken diyalog ise ylllar sonra bir oğlu olduğunu öğrenen Türk babanın "Allah bana bir oğul bahşetti." demesi ve bu duruma çok sevinmesidir.

- 00:28:55 - 00:30:25 aralığındaki sahnede karışan çocuklar iki haftalığına birbirlerinin yerine geçmek için hazırlık yapmaktadır. Türk anne kızına giderken yanında götürmesi için bir bavul dolusu yiyecek hazırlamıştır, Alman anne ise oğluna bir sözlük, ilaç ve iletişim halinde kalmaları için telefon vermiştir.

- 00:32:34 - 00:35:00 aralığındaki sahnede çocuklarını iki haftalığına takas etmek için Türk aile, Alman ailenin yanına gitmiştir. Alman anne Türk misafirlerine baklava yapmıştır ama baklava 
o kadar kötüdür ki, Türk baba yerken zorlanmıştır. Sahneden Alman ailenin boşanmış, Türk ailenin ise geleneksel aile yapısına sahip olduğu anlaşılmaktadır. Türk baba Alman aileye "Bir oğlunuz olduğu için gurur duyuyorsunuzdur” diyerek Türklerin erkek evlada daha çok önem verdiği algısı oluşturulmuştur.

- oo:35:56 - 00:36:26 aralığındaki sahnede çocukların iki haftalığına takası için kızlarını Alman ailenin yanına bıraktıktan sonra Türk aile arabada evlerine geri dönmektedir. Baba, anneye Alman ailenin evinde neden konuşmadığını sormaktadır. Annenin cevabı "Ne diyecektim, Ayşe'nin yeni annesi gibi kısa etek giymesinin yasak olduğunu mu diyecektim?” şeklinde olmuştur. Baba ise "O başka, yetişkin kadınlarda başka!" şeklinde bir cevap vermiştir. Anne ise bunun üzerine kendisinin de mini etek giyeceğini söyleyince, baba olmaz diyerek onun bir Türk kadını olduğunu söylemiştir. Evin küçük kızı (Dilek) ise Almanların evinin daha büyük olduğunu söylemiştir.

- 00:38:53 - 00:40:08 aralığındaki sahnede Türk aile evlerinde, Alman ailenin yanında büyümüş oğulları Dominik ile sofrada oturmaktadır. Anne akşam yemeği için Arnavut ciğeri, köfte, işkembe çorbası ve şiş kebap hazırlamıştır. Ancak Dominik masadakilere "Sebze de yiyor musunuz?” diyerek vejetaryen olduğunu söylemiştir. Baba, Dominik'e yarın onunla pazara gelip gelmeyeceğini sorduğunda ise Dominik'in cevabı "Seve seve ben de gelirim Erdal." olmuştur. Babasına adı ile hitap ettiği için masadakiler şaşırmış ve babası onu "Baba diyeceksin oğlum!” diyerek uyarmıştır.

- o0:54:20 - oo:56:06 aralığındaki sahnede Dominik iki haftalığına kendi okulu yerine Türklerin çoğunlukta olduğu Ayşe'nin okuluna gitmeye başlamıştır. Dersin konusu öğrencilerin örnek aldıkları kişiyi sunum yapmalarıdır. Sınıftaki Türk öğrencilerden birinin örnek aldığı kişi bir rap şarkıcısı iken, Alman olarak büyüyen Dominik’in örnek aldığı kişi insan hakları savunucusu Mahatma Gandhi'dir. Sınıftaki Türk öğrenciler Dominik'le Gandhi'yi örnek aldığı için dalga geçmektedir. Türk öğrenciler salaş kıyafetli, asi gençler olarak gösterilirken, Alman kültürü etkisinde kalan Dominik kültürlü, sakin bir kişilik olarak yansıtılmaktadır.

- 01:06:46 - 01:08: 40 aralığındaki sahnede evin büyük kızı Fatma için görücüler gelmiştir. Dominik'e bu birliktelik için ne düşündüğünü sorduklarında birbirlerini tanımadıklarını, bu birlikteliğin iyi mi kötü mü olacağını en iyi onların bileceğini söylemiştir. Bunun üzerine baba “Türkiye'de aile her şeydir, buradaki gibi değil. Aile gençler için en iyisini bilir." diyerek oğluna ögüt verir. Bunu kavramakta zorluk çeken Dominik bir başka görücü geldiğinde yine aynı tavrını sürdürür. Baba bu sefer ona "Bu başka bir kültür, kabul etmek zorundasın.” diyerek kizar.

Sahneler izletilirken birtakım etkinliklerin yapılmasına özen gösterilmelidir. Örneğin belli bir sahneden sonra o sahnede yer alan kültürel içerik ile ilgili sorular sorulabilir.

- Örn.: İzlediğiniz bu sahnede Türk ve Alman anne arasındaki farklar nelerdir?

Önceden hazırlanmış çoktan seçmeli sorular, boşluk doldurma veya doğru-yanlış testleri öğrencilere dağıtılarak, sahneleri izlerken alıştırmaları yapmaları istenmesi faydalı olacaktır.

- Örn.: Türk ailesi muhafazakâr bir yapıya sahiptir. (D) 
- Örn.: Alman anne çok iyi yemek yapmaktadır. (Y)

- Örn.: Alman babanın mesleği tir.

Sahneler izletildikten sonra da öğrencilere birtakım etkinlikler yaptırllarak izlenenlerin pekiştirilmesi sağlanmalıdır.

- Örn.: İzlediğiniz sahneler hakkında kısa bir özet yazınız.

- Örn.: İzlediğiniz sahnelerden Alman ve Türk aile yaşamı hakkında neler öğrendiniz?

- Örn.: İzlediğiniz sahnelerde iki kültür hakkında ne gibi ön yargılar bulunmaktadır? Bu ön yargıların nedenleri neler olabilir ve bu ön yargılar nasıl önlenebilir, partnerinizle tartışınız.

Sahnelerde yer alan kültürel içerikler kısaca değerlendirilirse, Türk ailesi muhafazakâr ve geleneksel bir aile yapısına sahip olarak yansıtılmıştır. Baba figürü otoriter ve erkek evlada daha çok önem vermektedir. Baba eşinin ve kızının kısa giyinesine şiddetle karşı çıkmaktadır. Filmde Türklerin aile bağları Almanlara göre daha sıkı ve güçlü olarak gösterilmiştir. Türk aile yapısında çocukların aile büyüklerine adı ile hitap edemeyeceği, bunun aksine Alman aile yapısında bunun normal olduğu yansıtılmıştır. Filmde Türk annesi iyi yemek yapabilen, klasik bir ev hanımı olarak gösterilmiştir. Ayrıca Türklerde yemek kültürünün Almanlara göre daha gelişmiş ve önemli olduğu da sahnelerden anlaşılmaktadır. Alman aile ise zengin, geleneksel aile yapısına sahip olmayan modern bir aile olarak gösterilmektedir. Alman anne istediği kadar kısa giyebilen, şık, iyi kazanan bir moda tasarımcısı, ama iyi yemek yapamayan bir kadın olarak yansıtılmıştır. Alman baba ilgisiz bir babadır ve otoriter değildir. Alman ailede yemek kültürü Türk ailedeki kadar gelişmiş değildir. Alman olarak büyümüş Dominik sakin, kültürlü iyi eğitim almış bir çocuk olarak gösterilirken, aslında Alman olan ama Türk kültüründe büyüyen Ayşe ise hırçın, zaman zaman kaba bir çocuk olarak yansıtılmıştır.

Filmindeki sahnelere bakıldığında filmin çoğunlukla kalıp düşünceler ve ön yargılar üzerine kurulmuş olduğu görülmektedir. Coşgun'a göre (2004: 11-12) kalıp düşünce ve ön yargılar iletişim sürecinde tarafların etkili bir iletişime geçmesine, birbirlerini anlamalarına ve farklıklar karşısında birbirlerini tolere etmelerine engel olmaktadır. Bunun sonucunda ise toplumsal gerginlikler yaşanmaktadır.

Tarafların sağlıklı şekilde iletişim kurmasına yardımcı olmayı hedefleyen Kültürlerarası Yaklaşım da kalıp düşüncelerle, ön yargılarla ve bunların aşılmasıyla yakından ilgilenmektedir. Tarafların birbirleri hakkında sahip oldukları ön yargıları bilmeleri etkili iletişim ve karşılıklı tolerans için önemlidir.

\section{Sonuç}

Dil ve kültür arasındaki sıkı ilişki, yabancı dil öğretiminde kültürün ve öğretiminin ön plana çımasına sebep olmuştur. Özellikle 8o'li yılların ortasından itibaren etkisini göstermeye başlayan "Kültürlerarası Yaklaşım” ile kültür yabancı dil öğretiminin bir parçası haline gelmiştir. Ancak temel öğretim materyalleri olan ders kitapları her zaman kültür öğretimi için yeterli olmayabilir. Yabancı dil derslerinde kültür öğretimi için kitaplara alternatif olabilecek en önemli materyaller arasında insan hayatını gerçekçi şekilde sunan ve bünyelerinde birçok kültürel unsur bulunduran filmlerdir. $\mathrm{Bu}$ bağlamda Alman yapımı "Kückückskind" adlı film kültürel açıdan incelenip, Almanca derslerinde kullanıldığı takdirde kültür öğretimine ne tür katkılar sağlayacağı ortaya koyulmuştur. 
Öncelikle film hem Türk hem Alman aile yapısını ele almasıyla öğrencilere iki kültürü kıyaslama imkânı sağlamaktadır. Hem Alman hem Türk kültürü hakkında bilgi edinmenin yanında, özellikle filmde Türkler ile ilgili birçok ön yargı ve kalıp düşüncelere yer verilmesiyle Almanların Türkler hakkında ne tür ön yargllara sahip olduğu da filmden öğrenilecek önemli kültürel içeriklerden bir tanesidir. Ön yargıların sağlıklı bir iletişimi engelleyen en önemli etkenler arasında olduğu düşünülürse, hedef kültürden biri ile iletişime geçileceğinde karşı tarafın kendi kültürümüz ile ilgili hangi ön yargılara sahip olduğunu bilmek, karşı tarafa daha toleranslı davranmaya imkân verecek ve bunun sonucunda da daha sağlıklı bir iletişim sürecine katkı sağlayacaktır. Film, öğrencilere Almanya'da yaşayan Türkler ile ilgili de birçok bilgi sunmaktadır. Böylelikle öğrenciler Türkiye'deki ve Almanya'daki Türk kültürünü kıyaslama imkânı da bulmaktadır.

Görüldüğü gibi “Kückückskind” filmi bünyesinde hem Türk hem Alman kültürü açsından birçok unsur barındırmaktadır. Kückückskind filmi, seçilmiş uygun sahneler ve sınıf içi etkinlikler eşliğinde gösterildiğinde kültür öğretimine birçok katkı sağlayacaktır. Bu sebeple hem yabancı dil derslerinde kültür öğretimine katkı sağlamak hem de öğretim ortamını zenginleştirmek için ders materyali olarak film kullanımına daha çok önem verilmelidir. Kültürel içerik açısından Kückückskind filmi ile benzerlik gösteren Alman-Türk ortak yapımı "Willkommen in Deutschland" adlı film de Almanca derslerinde kültür öğretimi için önerilebilecek filmler arasındadır.

\section{Kaynakça}

Aime Toth, C. (2010). Verstehen durch Hören und Sehen. Potenziel und Einsatz authentischer Spielfilme im Unterricht Deutsch als Fremdsprache, (Bitirme Tezi), Viyana Üniversitesi, Viyana.

Aksan, D. (2009a). Anlambilim: Anlambilim Konuları ve Türkçenin Anlambilimi. Ankara: Engin Yayın Evi.

Aksan, D. (2009b). Her Yönüyle Dil. Ana Çizgileriyle Dilbilim. Ankara: Türk Dil Kurumu.

Alpar, M. (2013). Yabancı Dil Öğretiminde Kültürel Unsurların Önemi. The Journal of Language and Linguistic Studies. 9(1). 95-106.

Avrupa Konseyi (2013). Diller İçin Avrupa Ortak Öneriler Çerçevesi- Öğrenim Öğretim ve Değerlendirme. Frankfurt/Main: telc, Milli Eğitim Bakanlığı.

Cinkara, E. (2016). Yabancı Dil Eğitiminde Kültürün Yeri. Erdinç Yücel, Hasan Yılmaz, M. Serkan Öztürk (Ed.) Yabancı Dil Öğretimine Genel Bir Bakış içinde, 110-118. Konya: Çizgi Kitabevi.

Coşgun, Ş. (2004). Kültürlerarası İletişim Sürecinde Kalıp Düşüncelerin ve Önyargıların Rolü: "Antalya'da Yaşayan Güneydoğulular ile Antalya Yerlileri Arasındaki Kallp Düşünceler ve Önyargılar", (Yüksek Lisans Tezi), Ankara Üniversitesi, Sosyal Bilimler Enstitüsü, Ankara.

Göktürk, A. (2016). Çeviri: Dillerin Dili. İstanbul: Yapı Kredi.

Internet Movie Database/IMDb, 2017. Kückückskind. http://www.imdb.com/ title/ tt2772026/?ref_=ttpl_pl_tt (05.12.2017).

İşcan, A. (2017). Yabancı Dil Olarak Türkçe Öğretiminde Kültür Aktarım Aracı Olarak Filmlerden Yararlanma. Türkiyat Araştırmaları Enstitüsü Dergisi. 58, 437-452.

Kalkan, H. K. (2014). KPSS ÖABT Almanca Ders Notlart: Ankara: Sözkesen Matbaa.

Leitzke-Ungerer, E. (2009). Film im Fremdsprachenunterricht: Herausforderungen, Chanchen, Ziele. Eva Leitzke-Ungerer (Ed.) Film im Fremdsprachenunterricht: Literarische Stoffe, interkulturelle Ziele, mediale Wirkung (Romanische Sprachen und ihre Didaktik) içinde (11-32). Stuttgart: ibidem Verlag. 
The use of film in teaching German as a foreign language in the context of intercultural approach / F. Çobanoğulları (pp. 726736)

Malaguti S. \& Thoma, N. (2012). Film und Filmmusik im Zweit- und Fremdsprachenunterricht. Einführung in den Themenschwerpunkt. Zeitschrift für Interkulturellen Fremdsprachenunterricht 17(2), 1-6.

Picture of Kückückskind (2016). Kückückskind filminin afişi. [Resim]. https://www.listal.com/ viewimage/9867475 (06.09.2021)

Tognozzi, E. (2010). Teaching and Evaluating Language and Culture Through Film. Italica, 87(1), 69-91.

Ying, W. \& Hai-feng, Z. (2012). The Application of English Movies in Higher Vocational English Teaching. Sino-Us English Teaching, 9(3), 1010-1014.

Yücel, E. (2009). Eine Kulturbrücke für den Fremdsprachenlerner. Konya: Çizgi.

ZDF \& Kost, Thomas (t.y.). kino.de. [Resim]. https://www.kino.de/star/ava-celik/\# (13.12.2017). 